This is an electronic reprint of the original article. This reprint may differ from the original in pagination and typographic detail.

Author(s): Pellinen, Jukka; Mättö, Toni; Sippola, Kari; Rautiainen, Antti

Title: $\quad$ Blame game or dialogue? Financial, professional and democratic accountabilities in a complex health care setting

Year: $\quad 2018$

Version:

Please cite the original version:

Pellinen, J., Mättö, T., Sippola, K., \& Rautiainen, A. (2018). Blame game or dialogue? Financial, professional and democratic accountabilities in a complex health care setting. Accounting, Auditing and Accountability Journal, 31(2), 626-650. https://doi.org/10.1108/AAAJ-03-2016-2449

All material supplied via JYX is protected by copyright and other intellectual property rights, and duplication or sale of all or part of any of the repository collections is not permitted, except that material may be duplicated by you for your research use or educational purposes in electronic or print form. You must obtain permission for any other use. Electronic or print copies may not be offered, whether for sale or otherwise to anyone who is not an authorised user. 


\section{emeraldinsight}

\section{Accounting, Auditing \& Accountability Journal}

Blame game or dialogue? Financial, professional and democratic accountabilities in a complex health care setting

Jukka O Pellinen, Toni Mättö, Kari Sippola, Antti Ilmari Rautiainen,

\section{Article information:}

To cite this document:

Jukka O Pellinen, Toni Mättö, Kari Sippola, Antti IImari Rautiainen, "Blame game or dialogue? Financial, professional and democratic accountabilities in a complex health care setting", Accounting, Auditing \& Accountability Journal, https:// doi.org/10.1108/AAAJ-03-2016-2449

Permanent link to this document:

https://doi.org/10.1108/AAAJ-03-2016-2449

Downloaded on: 19 J anuary 2018, At: 02:16 (PT)

References: this document contains references to 0 other documents.

To copy this document: permissions@emeraldinsight.com

Access to this document was granted through an Emerald subscription provided by emerald-srm: 306933 []

\section{For Authors}

If you would like to write for this, or any other Emerald publication, then please use our Emerald for Authors service information about how to choose which publication to write for and submission guidelines are available for all. Please visit www. emeral dinsight. com/authors for more information.

\section{About Emerald www.emeraldinsight.com}

Emerald is a global publisher linking research and practice to the benefit of society. The company manages a portfolio of more than 290 journals and over 2,350 books and book series volumes, as well as providing an extensive range of online products and additional customer resources and services.

Emerald is both COUNTER 4 and TRANSFER compliant. The organization is a partner of the Committee on Publication Ethics (COPE) and also works with Portico and the LOCKSS initiative for digital archive preservation.

*Related content and download information correct at time of download. 


\title{
Blame game or dialogue? Financial, professional, and democratic accountabilities in a complex health care setting
}

\begin{abstract}
Purpose: This article investigates how the complexity of the network governance setting affects accountability practices. We pay particular attention to the organizational characteristics that may enable a common understanding of multiple accountability relationships, or lead to problems in reconciling competing forms of accountability, thereby appearing as blame game type behavior.

Design: We conducted a case study with 31 semi-structured interviews in a Finnish health care organization (FHC) that offers basic public health care services. The organization represents a co-operative arrangement with the main city and three smaller municipalities. The FHC has faced difficulties in balancing budget constraints with the provision of statutory care to citizens. This case is analyzed with the help of theories relating to accountability, the blame game, and dialogue.
\end{abstract}

Findings: We found that in the FHC operating under austerity constraints, attempts to reconcile financial, professional, and democratic accountability were made but, instead of dialogue and consensus, the different stakeholder groups resorted to defensive tactics in order to protect their resources, position, or sense of professional obligation. We suggest that in a context of network governance, accompanied by an increasing emphasis on financial accountability, organizational practices are susceptible to conflicting accountabilities and behavior characterized in this paper as a blame game.

Originality/value: The study contributes to the empirical studies on accountability in the new public governance context by analyzing the complex accountability relations between stakeholder groups with different agendas. We suggest organizational characteristics that may exacerbate conflicts between different stakeholder groups and prevent constructive dialogue. Furthermore, the study analyzes the composition of democratic accountability within the studied organization.

Keywords - Case study, accountability, responsibility, health care, blame game, network governance 


\section{Introduction}

In recent decades, public governance reforms have largely been analyzed through the concepts of the public financial initiative and new public management, where the central idea is to extend the use of management accounting practices applied by firms to public services and governance (Lapsley, 2008; Lapsley et al., 2003; Kurunmäki and Miller, 2011). Skepticism about the effects of these changes on accountability practices is clearly evident in the public-sector accounting research (Chua, 1995; Cochrane, 1993; Cordery et al., 2010; Ezzamel and Willmott, 1993; Gray and Jenkins, 1993; Humphrey et al., 1993). While this has led to a widespread recognition of the shortcomings of performance measures in portraying accountability (e.g., Messner, 2009; Roberts, 2009), there is little research that examines the interplay of the different forms of accountability, such as financial, professional, and democratic forms of accountability, in complex public organizations.

This study aims to narrow this research gap by examining the evolving nature of the accountability relations in a municipal health care organization in Finland. There has been a trend since the 1990s in the organization of public services to move from vertically governed and hierarchical state entities toward the co-ordination of networks, and this trend has been widely analyzed in policy studies (Papadopoulos, 2003; Pierre, 2000; Rhodes, 1997, 2007). However, network organization forms that are integral to new public governance affect the practices of financial, professional, and democratic accountability (Almquist et al., 2013; Hodges, 2012). According to Hodges (2012, p. 42) "Changing political and economic structures of the public services have led to increased complexity in defining the scope and nature of both vertical and horizontal accountabilities." There are only a few studies in accounting of such network governance contexts (Cordery et al. 2010; Kurunmäki and Miller, 2011). Earlier literature suggests that changes in governance, such as those from bureaucratic models to network co-ordination approaches, can weaken democratic accountability (Pierre, 2000; Rhodes, 1997). Rhodes (1997; also 2007) predicts that the complexity of current public-sector organizations erodes accountability because the institutional complexity of network structures obscures who is accountable to whom and for what. At its worst, this leads to growing governance problems that limit the ability of public-sector managers to comply with multiple accountability demands, and thus act effectively. Further, complex organizational forms may promote sub-optimization, individually varied understandings of responsibility or democratic accountability, encourage avoiding responsibility, and present ample opportunities to shift blame between stakeholders (Hood, 2002, 2011).

However, a reform involving moving from bureaucratic governmental entities to network organizations may also involve an attempt to move beyond narrowly understood (e.g., financial or managerial) accountability relations toward widely understood and balanced accountability (or holistic accountability, see Cordery et al., 2010) to multiple stakeholders. Kurunmäki and Miller (2011) suggest that management accounting can facilitate integration between network partners. Typically, however, the related requirements for creating commonly shared values, open dialogue, an estimation of the impact on the environment, and a consideration of a range of stakeholders other than hierarchical superiors have not been 
realized (O’Dwyer and Unerman, 2007; Cordery et al., 2010). Although previous studies in accounting have conceptualized different forms of accountability (Sinclair, 1995; Ahrens, 1997; Roberts, 2009;) or noted potential conflicts between them (Ahrens and Chapman, 2002; Kurunmäki, 2004; Messner, 2009; Mutiganda, 2013), there remains a need to understand how an increase in organizational complexity affects accountability relations, and how the different forms of accountability can be reconciled.

A distinctive feature of the healthcare sector is that the services are in the hands of strong professional bodies. Doctors and nurses have considerable autonomy in terms of the work processes governing caring and healing. Increasing demands for financial accountability in the context of health care could give rise to conflicts with professional accountability. The possibility of such conflicts has led to social practices that can sometimes seem irrational, and apparently motivated by the protection of the status and autonomy of the ruling profession within the organization (Chua, 1995; Kurunmäki, 2004; Llewellyn, 1998; Mutiganda, 2013). In addition, the possibility of ethical problems concerning the use of performance measures in enforcing managerialism and financial accountability in public-sector organizations has been recognized (Messner, 2009; Roberts, 2009).

We conducted our case study in a Finnish health care organization (FHC) where four municipalities (main city and three smaller municipalities) co-operate to deliver basic health services in the region. The FHC operating context has elements of both hierarchy and network, the network elements including the four controlling municipalities, special health care units in the area, a city hospital, and other city health care units (see Appendix 1). The governance of the FHC involves the city taking the lead over the three smaller municipalities in the region. The governance structure is justified by the promise of better services and lower costs. The city population and service needs have been growing for many years but, at the same time, the city has become indebted and now struggles to balance its budgets. Therefore, the management context of the health center is defined by the economic austerity policy of the city and the contradictions between financial, professional, and political objectives and the related accountabilities coming to a head.

The case analysis focuses particularly on the differences between financial, professional, and democratic accountability relations and also on the potential outcomes of emphasizing these relations differently within the case organization. We examine the different forms of accountability in the FHC operating under network governance. We aim to analyze the multitude of accountability practices in the field, the points of conflict between them, as well as how they might be reconciled (e.g., through a blame game or with dialogue). Our research questions are:

What are the different accountabilities and how are they reconciled in a public health care organization?

Why does a given form of reconciliation take place? 
How does the complexity of a network health care setting affect accountability practices?

The paper is structured as follows. The following section provides an overview of the concepts of responsibility, accountability, and the different strategies for conducting the blame game as a result of reacting to the interplay of different accountabilities in a complex health care setting. The next section presents the case and the methods of data collection. The paper then presents the complex situation between the different forms of accountability and seeks to analyze different practices of reconciliation through the empirical data, before discussing the findings and presenting the conclusions.

\section{Multiple accountabilities, the blame game, and dialogue}

\section{Multiple accountabilities and responsibility}

Responsibility and accountability are ethically charged concepts that have often been used interchangeably. According to Mulgan (2000), however, responsibility mainly refers to the internal and personal aspects of moral obligation whereas accountability focuses on external justifications, sanctions, and liabilities to administrative and political superiors.

According to Butler (2005), an individual's perception of responsibility and the inner self is constructed through dialogue with other individuals: "by virtue of the relation to the Other that is established at the level of my primary and irreversible susceptibility" (Butler 2005, p. 88). Further, the different perceptions of responsibility among individuals and groups lead a society to be influenced by several types of ethos. If one group claims their ethos is universally right, social intercourse between the groups can lead to moral conflicts and "ethical violence" (Butler 2005, p. 5).

moral questions arise only when the collective ethos has ceased to hold sway. ... although the collective ethos is no longer shared ... it can impose its claim to commonality only through violent means. (Butler 2005, p. 4)

Bovens (1998) raises the notion of the "active form of responsibility" where an individual acts as both a manager or employee and a citizen in parallel. Accordingly, the individual might be placed in a conflicting situation if a professional accountability for outcomes conflicts with the personal notion of responsibility toward conscience, peers, and citizens (pp.149-164). In such a situation, choosing a legitimate course of action can be difficult. However, loyalty to one's superiors could be considered a primary virtue since without it organizations would falter in accomplishing their goals. According to Bovens (1998), an individual could actively respond to such conflicting situations by resigning, refusing to carry out instructions, whistleblowing or "tinkering with the structure" (pp. 176-220), thereby relieving personal feelings of guilt or shifting blame for poor outcomes (see also Cooper and Johnston 2012; Hood, 2002). 
Bovens $(1998,2005)$ characterizes accountability as "a social relationship in which an actor feels an obligation to explain and to justify his or her conduct to some significant other" and Borowiak (2011) uses the term punishability to refer to the extent that the blame and sanctions can be placed for one's behavior and its effects. Therefore, punishability is associated with a particular form of accountability if sanctions are triggered by a failure to meet the expectations of the accountability holder. Although accountability expectations are often presented through performance indicators, several researchers have warned about overemphasizing accountability through a limited set of indicators as doing so obscures the actual complexity of organizational, socially constructed reality (Cooper and Johnston, 2012; Roberts, 2009).

There is a large body of literature addressing problems generated by an excessive focus on managerial and measurable forms of accountability. Cooper and Johnston (2012) note that the mere provision of information is not accountability, and how accountability also encompasses decisions with an impact on oneself and others. Roberts (2003) differentiates between the hierarchical and socializing forms of accountability. Hierarchical forms of accountability involve achieving certain norms and standards provided by, for example, accounting. In contrast, the socializing form of accountability is more concerned with the recognition of the self and others, particularly how somebody appears to be responsible. In his later work, Roberts (2009) argues that the increased focus on transparency, and the resulting focus on performance based accountability, could make blame avoidance (see Hood 2011) a rational choice on the individual level. In Roberts' (2009) view, blame gaming stems from the recognition of the negative organizational consequence of over-zealous pursuit of transparency. Another, psychological reason to resort to shifting the blame is presented by Cooper and Johnston (2012): When faced with bad results or failure to meet a set ideal, a person could turn his/her self-criticism into a need to find others on whom to project all that is inadequate and which violates the sense of personal perfection.

In this paper, the term professional accountability refers to work-related self-control and professional expertise as a foundation for both individual decisions and organizational effectiveness (Romzek and Dubnick, 1987; Sinclair, 1995). Professional accountability also touches upon internal aspects of responsibility, in that it involves the professional's ethical working principles and personal feeling of liability and responsibility toward those he or she works for, or with. For example, in the highly specialized and independent medical profession, this sense of responsibility might be directed toward patients, peers, or clients and there could be conflict between the accountability to the profession and the lay representatives of the public, for example, regarding resource consumption over time. Because of the potential conflicts in external accountabilities, many such professionals feel primarily accountable to themselves, to their personal values, and to their conscience (Day and Klein, 1987). However, Romzek and Dubnick (1987, p. 229) note:

...public officials must rely on skilled and expert employees to provide appropriate solutions. Those employees expect to be held fully accountable for their actions and 
insist that agency leaders trust them to do the best job possible. If they fail to meet job performance expectations, it is assumed that they can be reprimanded or fired.

Accountability is also context and organization specific (Roberts and Scapens, 1985; Romzek and Dubnick, 1987). In the public sector, accountability essentially concerns the relationship between citizens and politicians, and, within the hierarchy of a public organization, between politicians and public managers (Barberis, 1998; Mulgan, 2000). According to Borowiak (2011), the primary function of democratic accountability is to provide a way for citizens "to exert discipline and control over governing bodies" (p.4). Prerequisites for democratic accountability are "the ultimate authority of a bounded political community of citizens" and institutions through which to operate. Thus, deficits in democratic accountability are caused either by the lack of citizen empowerment or poorly designed accountability mechanisms (see Borowiak, 2011, p. 4). Smyth (2012) notes that in such situations, citizens sometimes seek to challenge the predominant form of accountability by active campaigning against institutionalized practices. Brown (2009) argues that if democracy is understood as ultimately empowering citizens, accountability designs based on dialogue and participatory forms of control have the capability to further the goal of democracy. If accountability is separated from the power of decision, it becomes empty (Borowiak, 2011; Cooper and Johnston, 2012; Lowe et al., 2012).

Sinclair (1995) analyzed top municipal managers and found that accountability is subjectively constructed, situation-specific, flexible, and a continuously redefined phenomenon comprising five different types of accountability: the political, public, managerial, professional, and personal. Recently, however, financial accountability has been emphasized as a key managerial issue in public management (e.g., Lapsley, 2008). Previous studies in accounting have largely concentrated on the contradictions between the financial and professional forms of accountability. For example, according to Llewellyn (1998), professionals in social care protect their autonomy at work by not delegating responsibility for budgets. Further, Broadbent et al. (2001) noticed a tendency for professional organizations to resist accounting and finance based changes. Hyvönen and Järvinen (2006) found in their case that budgetary bias and old budgeting practices prevailed in hospital budgeting, that is, they were incorporated into the new budgeting model. Mutiganda (2013) noted that financial accountability clearly related to budgetary limits, while professional accountability is spread among the medical top managers, doctors, and nurses, indicating a decoupling of these two accountabilities. Kurunmäki (2004), however, found the integration of accounting knowledge and medical knowledge among clinical professionals to have positive effects. In order to achieve this integration, Goddard (2005) sees it as important to change the governance mentality of public-sector officials from being conformance centric to performance centric, and to develop budgeting practices (and associated accountability mechanisms) accordingly.

The contradiction between professional and financial accountability has been well established in public-sector studies. Democratic accountability, however, deserves more research attention especially when studying complex health care organizations under austerity 
conditions. In one of the few studies to address democratic accountability at the municipality level, Ahrens and Ferry (2015) studied the Newcastle City Council which delegated some responsibility for the focus of budget cuts to stakeholder groups, thereby dispersing accountability and reducing the perceived negative effects on service clients. Dispersing accountability can also be seen as dividing, shifting, or sharing the potential blame for the budget cuts among a wider range of actors (cf. Hood, 2011).

\section{Blame game and dialogue}

While public organizations are exposed to different initiatives targeting reform, transparency, and clearer accountabilities (Lapsley, 2008; Kurunmäki, 2004), Hood (2011) notes that pinpointing blame and finding the right people responsible in complex public organizations can be difficult. Further, Hood (2011) states that people are, by nature, averse to blame and often seek to avoid it to retain their chances of re-election, collecting bonuses, retaining a job, or safeguarding operating conditions, or their reputation. This raises the issue of a blame game, which involves a range of different actions and strategies utilized to avoid (public) blame, often with relatively little concern for organizational efficiency (see Hood, 2002; 2011).

Hood (2011) differentiates between three strategies that individuals, groups or organizations use to shift blame: presentational strategies, agency strategies, and policy strategies. Together these three strategies of blame avoidance constitute a set of actions that is called the blame game, which involves various actors attempting to place the blame on some other person, entity, or circumstance. Hood (2011) associates presentational blame avoidance strategies with the rhetorical dimension of politics and management, and also to the correct framing of arguments. One presentational strategy to avoid blame is to diminish the problem for which one is potentially blamed by presenting it as a minor setback or short-term issue that can deliver benefits in the long term. One might also present credible claims as to why a particular officeholder is not to blame for the incident. Other presentational strategies include deliberately inaccurate reporting, and making accounting disclosure opaque so that it is difficult to make precise claims against any specific person.

In contrast, agency strategies aim to promote blame avoidance by utilizing the responsibility guidelines of the public organization. This involves the delegation of activities that will attract blame and retaining activities likely to earn credit. Other examples of agency strategy include working in groups in a way that diminishes the opportunity to assign blame to an individual, or creating multi-agency arrangements in public services ${ }^{1}$ that make "shuffling blame about" possible or make it "disappear" between the different organizational entities

\footnotetext{
${ }^{1}$ Hood (2011, p. 95) refers to institutional partnerships and other arrangements that make several, separate organizations jointly responsible for a service as a "joined-up government". These types of arrangements relate to public organizations, although in some cases they extend to the business sector or other independent bodies. Our case involves a health care organization working in a network governance context that Hood (2011) might label a "joined-up" arrangement.
} 
(Hood 2011, p. 32). In addition, Hood (2011) considers the constant transfer of officeholders or change in organizational arrangements to be a type of agency strategy designed to avoid blame: By the time blame can be assigned to an entity or an individual, the subject in question has already been replaced.

Policy strategies rely on procedures and office guidelines. They involve a "selection of policies and operating routines that minimize institutional or individual blame" (Hood 2011, p. 31). Policy or operational strategies include obscure program targets and processes as well as the protocolization of practices so that exact, measurable results and individual blame can be avoided, or hidden behind bureaucratic practices, ideals, and protocols. Examples include formula-driven budget allocations or rigid protocols in place of independent professional judgment.

Referring to public-sector organizations or governmental bodies, Hood (2011) distinguishes four types of individuals that either utilize blame avoidance strategies, or are the target of those strategies. These are the top managers in public-sector organizations, public-facing case-handling professionals, people hidden from the public eye such as accountants, middle managers, and resource allocators and finally, the civil society consisting of those who scrutinize the public services such as clients, voters, and patients. Hood (2011) does not state explicitly where politicians fit into this four-level classification of actors, although he seems to imply that they are part of the group of top managers. Owing in part to national differences (i.e., in Finland, the city mayor is not a politician), in this paper, municipal politicians are considered a special group that overlaps with civil society and the top management. While politicians oversee the public organizations and demand value for money in their public speeches, they also act in the bodies that provide the public organization with its budget and operating guidelines.

The four groups of actors mentioned have various opportunities to utilize the three different strategies of blame avoidance (Hood, 2011). The top managers are able to utilize all three; they can appoint the right people to positions where blame is likely to be attributed if things go wrong. They make use of different forms of rhetoric when presenting themselves to the public. Finally, they are also able to shape the organizational structures to allow blame to be dispersed into complex organizational structures. Professionals, on the other hand, often utilize the presentational blame avoidance strategy in a way that shifts the blame back upwards; professionals may blame bad orders, flawed policies, time-consuming operating systems, or inadequate resource allocations, for example. The third group, consisting of middle level managers, financial administrators, and other supportive personnel, may find the blame placed on them from both the top management and the professional level. This, however, also gives them the chance to shift blame in multiple directions, including sideways if the organizational structure permits. When shifting blame upwards, they tend to utilize agency strategy to associate top management with every decision that might carry the risk of blame. When blame is to be shifted downwards to professionals, they utilize a policy strategy and refer to operating guidelines and organizational rules to point out mistakes in the professional's work (Hood 2011). 
Blame gaming behavior utilizes the inaccuracies of accountability design in a complex organization (see Roberts, 2009). However, Gårseth-Nesbakk and Kjærland (2016) note that resorting to blame game tactics may have unforeseen and counter-productive effects. They suggest that once blame game is initiated, subsequent developments cannot be controlled due to complexity of the context in which it is used. For example, there are limits to how much blame can be shifted to others: even if responsibility were to be formally delegated, the voters might still hold a key politician, for example, responsible for the outcome (Hood, 2011, 21).

Shared understanding of accountability and blame sharing (delegating some but still accepting part of the possible blame) can be prerequisites for constructive debate and organizational development. Instead of actors utilizing different blame game strategies, an organization might be able to concentrate on solving the problematic issues. Building shared language and exchanging ideas across the parties to accountability relationships is called intelligent accountability (Roberts, 2009) or dialogue (Messner, 2009). In this paper, we use the latter term. Explaining and reasoning are central to dialogue, and to creating common understanding of the opportunities and constraints affecting accountability relations. Dialogue fosters aspects like a common vision of service production, encouraging individuals to overcome situations characterized by competing accountabilities (Goretzki and Messner, 2016). This common vision also suggests co-operation, thereby sharing possible political blame among, and possibly dispersing accountability to, a wider selection of actors (see Ahrens and Ferry, 2015; Hood, 2008). In this paper, we combine the analysis of different forms of accountability with the notions of the blame game and dialogue.

\section{Methodology}

Within the context of a health care case organization working within a network setting, a field study of accountability and accounting was conducted between February 2013 and March 2014 in the FHC providing basic health care services (Appendix 1) for about 150000 people living in the municipal area of a main city and three other smaller municipalities in Finland. The FHC has 12 health care units (clinics) within its area, most of which operate from 8 am to $4 \mathrm{pm}$ on weekdays, and it currently has a net budget (net expenses after fees from customers) of about EUR 80 million and about 1,000 employees. The four municipalities involved finance the FHC jointly according to a cost-sharing contract, but in practice the FHC operates under the control of the main city organization. Elected political decision makers are involved in the budgeting process through defining the budgetary limits for the organization.

We conducted 31 interviews between 2013 and 2014 (see Appendix 2). Further, we analyzed accounting reports, budgets, internet reports, and local newspaper articles. We mainly used qualitative data to obtain a broad appreciation of the case events, but also included some quantitative data in accordance with case study principles (see Yin, 1984). The interviews were semi-structured and conducted by the authors. Some of the interviews had two 
interviewers or interviewees present and they often resembled an active discussion more than a recording of precisely formulated questions and responses. These features permitted the subject matter to be viewed from different angles and the avoidance of any single type of vocabulary (Alvesson, 2003).

Our research project started in early 2013 with the first set of interviews in the FHC organization. The first nine interviewees in seven interviews were mostly managers and people responsible for the financial administration at the FHC. These interviews provided an understanding of the financial administration of the city's health care services. Another important aim was to focus our research questions on the most promising research phenomena. We asked the interviewees questions on different control systems in use with the financial administration, the performance measures used, the role of budgeting in health care, and on the development needs of the financial administration of the health care system. Each interview was transcribed and analyzed. Following the transcription, each researcher reviewed the interview material and sorted the collection of remarks into themes. These themes were then compared to enhance the validity of the interpretations. Therefore, the analysis of interview data included features of content analysis, such as categorization, and ethnographic analysis that included trying to understand the socially constructed organizational reality (see e.g., Silverman, 2001, pp. 122-129).

A major theme raised in the nine interviews was the role of budgeting and the various issues arising from it (e.g., difficulties with getting professional groups to take responsibility for the budget, under budgeting resulting in part from ambiguous input from the health professionals, and a lack of awareness of budgetary limits among some of the deputy chief physicians). The analysis revealed the different accountabilities and the processes creating them to be a very interesting research topic.

The second set of interviews was conducted in the autumn of 2013 in order to extend our view of the professional accountability perceptions and the discrepancies between them. In research project meetings with the FHC representatives, three health clinics were selected from the pool of 12 clinics in the area. Six people from each health clinic were interviewed separately, including two nurses, two doctors, a head nurse, and the deputy chief physician responsible for the health clinic. The interviews covered several issues, including views on accountability and responsibility, the clinic's targets, the measurement of those targets, budgeting control, budgetary reporting, and the main problems and development needs of the health clinic. Finally, in order to obtain a view of the financial and democratic accountability developments, in a third round of interviews, six people from the city management, were interviewed early in 2014.

In addition to the interviews, the research group collected material such as reports, cost estimates, the cost driver and cost allocation data used in the FHC, population data for the city area, the budgets and economic forecasts for 2013, city strategy papers, and the number of patient visits handled by doctors and nurses. The research group also collected local newspaper articles on aspects of health care to provide internal background information, and 
also contacted the Regional State Administrative Agency to obtain reports on the service levels of the FHC.

This article pursues data-driven theory refinement relating to the accountability literature through case research findings. The validity of the research is increased through multiple rounds of interviews focusing the research questions in addition to independent analysis conducted by four researchers. Further, the rich case description included aims to convey the "convincingness" (Golden-Biddle and Locke, 1993) of the research. Convincingness is established when research is able to convey that the researchers have been in the case organization, understand the behavior of the actors, and can make plausible arguments based on case data interpretations. Further, critical reflection upon the assumptions made in earlier literature or by case actors helps avoid bias and to deliver contributions (Golden-Biddle and Locke, 1993; McKinnon, 1988).

\section{Case}

\section{Case setting}

Finland's 313 municipalities are responsible for organizing basic health care for the 5.5 million citizens of the country. The Constitution of Finland together with the Health Care Act mandates equal quality and availability of basic health care regardless of the region where the citizen lives. The regional state authorities monitor that the health services are meeting the required standards of service delivery, and can fine municipalities failing to do so. However, the exact organization of local health care provision varies in Finland; it may, for example, be organized as a type of network organization together with other municipalities, or through private corporations, or the municipality may decide to provide its health care by itself. Regarding the financial constraints on health services, the Finnish Municipality Act requires that municipalities balance their finances or, in the worst case, a municipality can be deprived of its autonomy and be compulsorily merged with another municipality.

In an attempt to improve efficiency and deliver budget savings, the FHC was founded in 2010 with the agreement of four municipalities to create a health care organization for the provision of basic health care services to the citizens of the region. The agreement required the three municipalities to transfer the responsibilities relating to the administration of health care services to the main city. As a result, the organizational structure became a complex combination of 11 hierarchical levels of the city and a network of four municipalities. From 2011 onwards, employees from the different health care areas were transferred to the main city's payroll and absorbed into its administrative processes.

The FHC organization is directed by the basic welfare board, which is an administrative entity of the main city. A basic welfare board is a typical Finnish administrative arrangement, where municipal politicians control the budgetary limits of a health care organization, make decisions concerning the provision of health care services (such as changing the number of 
clinics in the municipality's area), and set the service guidelines for social and health care in the area. In Finland, a basic welfare board is used as an administrative entity irrespective of the governance structure of health care in the area (i.e., network or single municipality). The basic welfare board in our case comprises 13 members from different political parties, all of whom are from the main city. The members of the basic welfare board are chosen from among the elected politicians on the municipal council; in Finland, municipal politicians often have several roles on different boards in the city. In addition, an advisory board referred to as a health care division operates under the basic welfare board, but has no real jurisdiction over administrative matters. The purpose of the health care division is to gather the budget proposals from the member municipalities and present them to the basic welfare board, which then decides on the final budgetary proposal to the main city council. The health care division comprises nine members, six of whom are political representatives of the main city, and three of whom come from the other member municipalities. The health care division liaises between the political administration of a health care organization, the city management, and the clinical professionals. As the influence of the surrounding municipalities in the FHC is limited to an advisory role in the health care division, this type of arrangement effectively transfers both the decision-making power and the responsibility for service provision to the main city.

Although the main city retains the administrative rights for service provision and the members on the basic welfare board, the joint agreement for health care service provision initially contained a stipulation that no single municipality could change the co-ordination of services, quality standards, the organization of activities, or regional health care service requirements without the consent of the other member municipalities. This, however, slowed down the administrative processes and ultimately resulted in a supplemental contract that increased the role of the basic welfare board and the administrative management, thereby strengthening the main city's mandate for action.

In Finland, a city mayor and deputy city mayor differ from politicians in that they are appointed by the municipal council as the officials in charge of the city administration. As such, they are not directly elected by voters, nor are they typically members of any political boards in the municipality. The deputy city mayor responsible for the field of health care supervises the implementation of the budgets and guidelines set by the basic welfare board. The city mayor is the highest-ranking official of the city management who directs the municipality, supervises the finances, and has the power of decision granted by the municipal council.

The Finnish Municipality Act states the municipal council is responsible for setting an annual budget for the next calendar year. The municipal council is also required to make and accept a financial plan for a minimum three-year planning period. The budget sets the financial and functional targets for the municipality. The municipality's budget must be balanced (or be in surplus) within a planning period (Finnish Municipality Act, ch.8, para. 65). The Finnish Health Care Act includes some supplementary stipulations on health care responsibilities 
(e.g., maximum patient waiting times). Regional authorities monitor the municipalities' service provision accordingly and ensure that legislation is complied with.

In the aftermath of the recent global financial crisis, marked by a growth in legislative requirements for municipal services and simultaneous governmental savings, our case city has had financial difficulties. In 2011, it recorded a deficit of about EUR 24 million, which amounted to a little over three percent of all expenditure. In 2012, the city deficit almost doubled to close to EUR 46 million, amounting to over six percent of all expenditure. In 2013, the deficit was about EUR 38 million, and during both 2014 and 2015, deficits of about EUR 13 million were recorded. Cuts to the basic health care budget have also been made during this period, creating further pressure on FHC employees.

\section{Multiple accountabilities in health care}

The city mayor emphasizes financial accountability. For example, the deputy city mayor in charge of social and health affairs states:

My boss measures my success only based on the fact of whether I stay on budget or not. If that budget overruns, it is a very bad situation. This is the fact. (Deputy city mayor)

In the FHC, as in many other health centers in Finland, the management of clinical professions has been separated. This means that doctors and nurses each have their own supervisors: for doctors, that means deputy chief physicians, and head nurses supervise nurses. One of the results of this arrangement is that the management of personnel is somewhat uncoordinated. Deputy chief physicians cannot directly manage nurses because they report to head nurses. Head nurses are not accountable for the budget, while deputy chief physicians ought to monitor the spending of their own clinic. However, the formal accountability for the budget and the service process rests with the director of basic health care services, who has not delegated budget accountability formally to the deputy chief physicians of the 12 clinics. One interpretation is that the budget responsibility is deliberately focused on one individual to enable the other members of the professional group to concentrate on their clinical work.

The responsibilities of the FHC's nurses include taking phone calls from potential patients, deciding on the right course of action (i.e., whether a patient sees a doctor, a nurse, or is treated at home), seeing patients themselves, and recording their actions on various databases. These include the national database for health care services that monitors the number of patient visits per clinic, the type of diagnosis made, treatment decisions and suchlike. The responsibilities of the doctors include seeing patients, recording their actions on the same databases as the nurses, being on call for emergencies, managing the ward, and performing special functions assigned to them. These special functions vary, and examples include visits to local schools, or providing an out-call service to designated nursing homes. 
Doctors and politicians are trying to keep the service level high; while the doctors do not usually concern themselves with costs of the services, politicians generally demand high levels of service at minimum costs. The city management, on the other hand, tries to keep the costs down. This generates a situation where accountabilities of the city management and the clinical professionals conflict. Finally, another institution that affects the situation is the Regional State Administrative Agency (RSAA) that monitors the legality of services and also directs, licenses, and oversees healthcare. It enforces a required quality level for treatments and monitors whether the various legislative metrics of the services are met. For example, it requires that non-urgent treatment is available for the patient within 30 days of contact. A director commented on the situation:

\begin{abstract}
Many times it is us [clinical professionals] that are worried about legality of the services and that patients get the care that is required. But then, it seems that city management doesn't care about that. They only care about services being provided cheaply. Also, it seems that the agency here [RSAA] is much stricter than elsewhere. These regional agencies seem to interpret the law differently; this further limits our options. (Director of basic health care)
\end{abstract}

While the day-to-day management of the city remains in the hands of non-politicians like the mayor and the deputy city mayors, the situation is further complicated by many municipal politicians having several different roles on the administrative boards of the city. These roles may have differing responsibilities and different forms of accountability; for example, a politician may drive budget cuts and cost savings in the city council, but as a member of the basic welfare board, he/she may try to argue for budget increases for health care.

Politicians in the city council and on the basic welfare board tend to think in terms of the meeting they are participating in. This results in contradictory behavior. And there are so many different agendas, I mean, it's not only the party politics that determine politicians' opinions, it is also regional politics, so politicians may be inclined to prevent the closure of a clinic in their constituency. (General health manager)

Clinical work involves several responsibilities and associated reporting processes. Deputy chief physicians hoped that the city administration would take political responsibility by issuing a statement to clinics confirming the budget cuts and demands for savings. This would shift the blame away from the deputy chief physicians to the city administration and politicians, thus constituting a type of blame sharing.

Personnel here seem to think that management of the clinic wants to pressure them as tightly as possible. They keep saying that we've always had the extra funding when we needed it, because we can't stop the public service. So, they want to see some representation from the city administration to come down here and confirm the crisis and the budget cuts. (Head nurse)

Clinical professionals reported an increase in performance measurement, mandatory statistical reporting, and financial accountability at the cost of good patient care. Examples 
include a new access control system with working time metrics, increased reporting responsibility to outside organizations, administrative responsibilities, demands for costcutting, and an increased emphasis on efficiency measurement.

As a doctor, I find it hard to accept that reporting our work to outside organizations is more important than finding the right treatment for a patient. It seems that nowadays, everything is more important than the patient. (Deputy chief physician)

A statutory care guarantee determines the content of the work of nurses, with the most important performance metric being telephone answer times. These are monitored and if the required performance level is not met, those responsible for not meeting the metric are required to explain themselves to administration.

It started from a simple thing: access control. Then came the phone call measurement. They want to know how quickly we answer the phone calls. Of course, we've always been measured to some extent, but now it's become so easy with computers and technical systems. (Nurse)

Modern patient work involves input into different clinical databases. This, in turn has enabled the city management to push financial accountability in the form of various performance measures to the clinical professionals irrespective of the budgetary control of individual clinics.

\section{Conflicting accountabilities and reasons for blame games}

Clinical professionals see their main goal as being the welfare of their patients. They would rather concentrate on the best possible care and seem to think that given the right volume of resources, savings will appear eventually. The belief is based on the assumption that by devoting sufficient resources to preventive care by treating the minor problems of today, and reserving the time for lifestyle instruction sessions, major problems could be avoided in the future. This highlights that financial or democratic accountability considerations can differ if considered from a short-term or from a long-term perspective. However, with the current pressure to deliver cost savings, preventive health services have been scaled back, prompting arguments like these:

If we could treat these patients like we want, if we had the time to really concentrate on their situation, I know that in 10 or 15 years we would see the results and there would be a real reduction in strokes and heart attacks. And treating a stroke: that really costs a lot. But now, we are forced to downsize all the time, even to a foolish degree and I tell you, in the future, we will see even higher costs. (Director of basic health care)

A former general health manager who had been relocated before the interviews following several budgetary issues seemed to have a similar view: 
We are ignoring some stuff that has to be taken care of in the future. By saving in the short term we are piling up stuff for the future. In a way, we are taking a loan that has to be paid off some time. (Relocated general health manager)

The situation between the city administration and clinical management is highlighted by the fact that the 2013 regional basic health care budget was cut by 10 percent by the city administration. The action created a gulf between the expected level of service and the expected cost cuts. A head nurse commented:

The budget is way too tight. The budget is even lower than last year's. This really does not seem good, our patient queues are increasing, and are now close to the regulatory boundary and that could be crossed. (Head nurse)

However, accountability for the budget is unclear; for many years, the case organization has under-budgeted its activities, and acquiring extra funding near the end of the year has become the way of doing things. Also, it may be that in the FHC, the steering influence of the budgetary control has diminished due to sanctions from the alleged overspending being actualized in the form of tighter budgets. Further, as budget responsibility has not been delegated formally to the deputy chief physicians in charge of the clinics, this creates an ambiguous situation concerning the meaning of financial accountability and may further promote emphasis on professional accountability at the operational level.

This under budgeting has been our way for years now. We just ask for extra funding every year when we realize that the budget is not going to hold. And I understand it now, the budget doesn't mean a thing; extra funding comes anyway. (Head nurse)

The budget is considered unrealistic by the personnel and the financial reporting is not trusted. The overhead costs designated to the clinic in particular are seen as distorted. Management at the clinics seems to be confused by the overheads, as these are not within the control of the clinic and are apparently hard to anticipate.

I do not even understand why these costs are put to us. What I would like to see is the salaries, equipment, and materials we have used so far. This would be realistic for me. These overheads, they seem to come at an unsystematic pace. When I think that we are on budget, suddenly there comes a sudden addition of overheads designated to our clinic and all of a sudden, we're way off. (Head nurse)

Well they do send the reports to us on a regular basis. I even try to follow them, but you cannot trust the reports coming from the financial administration. You can't believe the numbers. It is a constant pain to try to follow the budget. On the one hand, we're required to be cost-conscious, but on the other, these reports do not give us any way of doing it. (Deputy chief physician)

There is clear indication of the clinical professionals' distrust of the financial information provided. Previous budgeting mistakes, ever increasing cuts to the budget and a lack of 
understanding about the principles behind the calculation of the overhead figures add to the ambiguous situation the clinical professionals perceive. This has led to the clinical profession to emphasize professional accountability in spite of the city administration's aim to increase the financial accountability in the organization. Further, clinical professionals direct blame toward the financial administration and city management for previous mistakes.

We had this error in the budget a while back. One cost item was left out of the budget, which amounts to over one million euros. You can think for yourself what this means to us. We have to stay on budget, while those making the budget leave out some numbers. We still have to pay the salary, even for those that are not included in the budget. (Director of basic health care)

There is a lot of collation and analysis of statistics in a health care organization. However, clinical professionals are loyal to each other and are careful not to disclose information that could potentially be harmful. The financial administration is deliberately excluded from the decision making. In addition, clinical management seems to continue to question the reliability of the financial administration's reports. This is evident in the reworking of budgetary reports into calculations by the clinical management. Hood (2011) characterizes such purpose-oriented reporting as a presentational strategy to initiate blame avoidance, while professional grouping and internal dialogue suggests an agency related strategy for diminishing individual implication. These reworked calculations are displayed without the approval of the financial administration in the health care division and ultimately, to the basic welfare board. Following Roberts (2009), we note that in complex organizations where managerial (or financial) accountability is opaque but over-emphasized, blame game type behavior might well be a rational choice; an actor is reconciling the conflicting situation in order to preserve self-integrity and the necessary resources for operational work (See also Cooper and Johnston, 2012; Hood, 2011; Messner, 2009). However, as a side effect, this kind of behavior contains an obvious risk of sub-optimization and even manipulation of numbers and reports:

\begin{abstract}
Our current general health manager is very enthusiastic about this (re-calculation of financial reports), but the problem with doctors is that they do not want to show these calculations to outside parties. Our relocated manager guarded these clinical calculations very carefully and I can already see that his successor is also somewhat reluctant to talk about them. (Deputy city mayor)
\end{abstract}

Overhead costs are distributed to individual clinics on the basis of full capacity. In our case organization, one of the problems resulting in part from a restriction on hiring substitute personnel is that most of the clinics are understaffed. This results in disproportionate overhead costs being attributed to a single patient visit, thus causing sub-optimization and distorted cost calculations.

In addition to the budget, the efficiency of the different clinics is evaluated through the metric of patient visits. This encourages the clinics to try to increase the number of patient visits to 
both nurses and doctors. This measure is seen to promote sub-optimization as the content of visits is not taken into account.

In our work, it may well be that the fewer the visits, the more efficient it is. This is because then the patient has his/her problems taken care of. (Head nurse)

There are doctors who take 4000-5000 patients per year, and then there are doctors who take only 2000 patients per year. But then, the measure doesn't take into account that some doctors like to have patients come three times for one thing at a time, and other doctors might take the time to handle everything in a single visit. While one doctor handles everything in 30 minutes, the other takes 45 minutes to handle these things in three separate visits. Although our system indicates three visits for the one guy and only one for the other, there's no question in my mind who was the most efficient. (Director of basic health services)

The financial manager views the deputy chief physicians in charge of individual clinics as largely ignorant of the budgeting and monitoring process. The budget accountability centers on the director of basic health care, while, according to the financial manager, deputy chief physicians mostly try to organize individual clinics using non-financial performance measurement metrics, such as waiting times, and the number of patient visits to a clinic. The financial manager seems to argue that doctors are resistant to change and that they should start to learn accounting. It is also an indication of a lack of dialogue, signaling that professional groups do not understand each other.

\begin{abstract}
Deputy chief physicians...they know little about accounting. It is actually a bit sad that we in the financial management have to fill them in and tell them where we are, on a monthly basis. We'd really need them to start learning about accounting; perhaps then they would understand what the numbers mean. The problem is, the power of the profession is really high, doctors think that because we've always done like this, there is no reason to change. They are always trying to resist different development ideas (Financial manager)
\end{abstract}

The clinical administration of the FHC is of the opinion that in this situation delivering cost savings in health services would require shutting down some of the health care clinics. However, any proposal to close some of the clinics results in political debates and, ultimately ends up being blocked by the politicians on the various boards of the city administration. Politicians seem to be reluctant to take the responsibility for a decision to weaken services, since that could weaken their chances of being re-elected.

Whenever we try to make a big decision about service coverage, like shutting down a couple of clinics to cut costs, we encounter political resistance and they keep saying that we must leave the service coverage untouched. It is difficult for a health manager to make any tough decisions when you don't get political support. (General health manager) 
Health care managers face the difficult situation of being accountable for the health care budget while trying to make cost savings in the contradictory context of municipal politics. The case of the former general health manager mentioned above who was relocated can be viewed as an example of politicians acting to secure their own position in terms of being accountable to the public. The relocation of officeholders is one example of the agency strategy for avoiding blame in Hood's (2011) typology. This strategy can be utilized in the form of dismissal (to shift blame to the person being dismissed), and by resigning, thereby avoiding a blame falling on oneself.

At the time, they (politicians) saw the manager's responsibilities in the organization as simply to be a cost-cutter. They didn't appreciate cost-effectiveness, as in doing an effective job or thinking about long-term cost effects, rather they wanted immediate cost efficiency. And now that I think about what has happened since (the relocation), I can already see that in one year, they (the FHC) are already overrunning the budget more than ever. (Relocated general health manager)

The general health manager reports to both the deputy chief mayor and the basic welfare board. Trust between these actors defines the shape of the accountability relations. The general health manager had a problematic relationship with the members of the basic welfare board, which eventually led to his relocation. The situation at the time was also noted in an internal auditing report of the organization:

There is no mutual point of view about development needs or activity targets. This observation includes both the trustees [political representatives of the municipalities] as well as the operative management. (Internal audit report 4/2013)

A local newspaper commented on the apparent conflict between administration and the operative management:

The position of the general health manager has been quite unstable for the last few years. The shop steward of the city's doctors' association commented that they [general health managers] haven't been given the industrial peace in their work, their authority has been constantly undermined and their decisions have been overturned by municipal politicians. (Local newspaper article 1.7.2015)

The situation at the FHC seems to be vulnerable to conflicts between forms of accountability and prone to blame shifting, an example being the conflict between the members of the basic welfare board and the general health manager. Between 2011 and early 2016, there were eight general health managers, two of whom were substitutes. This issue has also been discussed many times in the local newspaper in articles concerning professional cliques, which report that doctors and their professional association resist candidates who lack a clinical background. The situation is further complicated by the expectations of the city administration and the politicians; consequently, the general health managers have found their position to be quite unstable during the last years. 
The conflict between the financial accountability advocated by the mayor and clinical professional accountability is also evident. The mayor's means are mostly limited to rhetorical speeches and budgetary control (resulting in even more emphasis on financial accountability) in a situation where most of the city's clinics are already understaffed, and the work in clinics is described in the local newspaper as strenuous 'salt-mine work.'

The vice manager of the doctor's union commented on the situation of the FHC clinics as being like working in a salt-mine... especially young doctors do not want to work there. The ratio of pay to volume of work is just so bad in the FHC...In the FHC area, understaffing and difficulties in attracting doctors for vacant positions have been a constant issue. (Local newspaper article 20.1.2014)

The views of the city management and the clinical profession concerning responsibilities are different, and politicians seem to condone tighter budgets in the basic welfare board. The media has started to disseminate the apparent difficulties inside the organization to the wider public.

A need for dialogue

... A shop steward for the city's doctors continues; "Doctors in the city do not trust the administration. They feel that the decisions made by the administration are in a constant flux. Also, it is clear that there is no willingness [on their part] to really get together and solve these issues [conflicts between administration and doctors] with mutual discussions" (Local newspaper article 1.7.2015)

I think it was about one and a half years ago that the mayor was talking to the clinical management team and said that the situation is dire, the situation needs to be improved, both in terms of mutual relationships and of budget control. He also said that if someone thinks that they're not accountable, or they don't want to be, they don't have to be here (in the organization). And I was there, too. And I looked at the expression on their faces [clinical professionals] and I already knew they weren't going to change a thing. (Deputy chief mayor)

This lack of dialogue between city administration and clinical professionals suggests that when two strong accountabilities conflict and common goals and blame sharing are absent, different parties reconcile the situation by utilizing the blame avoidance strategies. One aim of such strategies seen in our case is to downplay financial accountability, action that comes close to resembling civil disobedience in terms of the vertical hierarchy. Another implication in our case is that loyalty to the profession and an individual sense of responsibility is stronger than loyalty to the organization, at least when the organization is both vertically and horizontally complex.

Demands for cost efficiency manifest as an internal debate between clinical professionals with the aim of reconciling conflicting accountabilities. In this situation, the essential goal is 
to keep different accountabilities aligned and make decisions that have the minimum effect on clinical leeway, while at the same time satisfying the city administration. Further, the relocated general health manager seems to aim to retain some influence over the processes.

I will have discussions with the current general health manager, and also discussions with the people in the main processes, in which we will agree what template we will have. I mean, it's the personnel cost, that is the biggest cost for us, so there will not be a problem, even here the service manager has the budget accountability. But we have agreed things, and that's how things work (Relocated general health manager)

It might seem strange that a relocated manager still considers it possible to influence the decision-making processes, and perhaps suggests some presence of unofficial power structures and reluctance to change. Moreover, the complex multi-agency arrangement of the FHC structure seems to allow for the relocation of a manager into a different position in the organization while retaining some influence and a close relationship with the city's doctors. The complexity of the context in which the FHC operates is highlighted by the point that in addition to the clinical professionals and administration, stakeholders in the FHC include the media and the political decision makers who represent the citizens.

\begin{abstract}
All the time, we have to try to find compromises and think about the process...if we can ignore some things, or move some tasks to be done by somebody else...But as I mentioned, there are not only the citizens, and politicians, but there is also the law. It is a very big pattern, and there is also the media, which is a big opinion leader. (Relocated general health manager)
\end{abstract}

The autonomy of the clinical profession is so strong that it does not need to take on development ideas from outside of the profession; the only time that outsiders are included in the talks is when they involve determining resources for the operations. Even in these situations, clinical professionals tend to strive for control over the discussion and terms.

Well, at least in my personal opinion, whenever I have tried to suggest some course of action or development idea, they (doctors) have been very cold, to the point of throwing me out of their meetings. For example, I tried to offer a development idea about coordination of closing times between clinics but nobody listened. (Development officer)

In the citywide organization (Figure 1 - Appendix 1), the city mayor and deputy mayor act as superiors to the general health manager, a position to date always occupied by a medical doctor. The city administration expects the general health manager to reduce costs, while at the same time the clinical professionals expect to be provided with reasonable resources to maintain the expected level of service for social and health services.

Municipal politicians expect the organization to provide good quality services at minimum cost. The municipalities expect to be provided with timely financial reports on the different areas of the FHC to assist their oversight responsibilities. However, some of the 
municipalities in the FHC were unhappy about the financial reporting provided by the main city:

... member municipalities need to be informed better of the developments in the FHC during the fiscal period. Timely and precise reports are needed to ensure that member municipalities can keep track of the expenses. ... a representative [of one of the member municipalities] stated "we shouldn't be forced to dig out the information from databases ourselves and try to calculate the different cost units from pooled data. For example, last year [2014] our expenses [from the FHC] were bigger than the agreed budget" (Local newspaper article 24.2.2015)

The health care organization has sought savings by closing health clinics for short periods, stopping the hiring of substitute staff, using group sessions for patients (when permitted by privacy law), and instructing patients on self-care whenever possible. In addition, in some health clinics, elements of the workload have been transferred from doctors to nurses and in some cases, a nurse has been hired in place of a doctor. Health care professionals see the situation as critical in terms of service level. The cost-saving measures initiated by the health care organization do not seem to have produced the savings expected by the city administration. Hence, the point where the service level starts to degrade is near. One of the directors of nursing services called for the politicians to take responsibility and initiate open dialogue with the citizens:

We do understand that the city is running out of money. But then, we would like the decision makers to tell the public that there is no more money, that we cannot get the same service anymore. Of course, we have tried to come up with different solutions to save where possible, but these are minor things. Like group sessions, temporary closures of clinics, and then there are restrictions on hiring substitutes. (Director of nursing services)

An important way for the city administration to enforce cost savings is through the human resource management function of the city. All recruitment, arrangement of temporary substitute personnel, and other decisions concerning the number of personnel and salary issues, have to be accepted there. The high salary cost of using substitute doctors combined with the scarcity of resources has forced the FHC to operate without a sufficient number of substitutes. Accordingly, the FHC has defined the critical functions for each main process, while the remaining functions are not given priority.

We have the staffing plans that we will make together...we have agreed for example how we take the substituting personnel. It means that we have to take care of certain critical functions, whatever our financial situation, because of patient security. (Relocated general health manager)

A new manager, responsible for health care services, tried to find solutions to the situation by holding both personal and small group discussions over three months with the staff of the FHC. In an effort to reconcile conflicting accountabilities, the manager also had a great deal 
of dialogue with the decision makers on the basic welfare board, aiming to teach them to recognize the health care issues affected by the decision-making processes. This implies the (as yet unrealized) potential of dialogue between professional groups to reconcile conflicting accountabilities.

\begin{abstract}
I had some good discussions with the basic welfare board, and I tried to bring the information to the decision makers from the viewpoints which are important in health care...also there was some understanding, at least partly, about the financial aspects. But then again, when we went to the budget negotiations in the autumn, it was never realized in practice, because the decision makers saw that now we have the budget frames here and we cannot go over these frames, even though we know what should be done. (General health manager)
\end{abstract}

Although the strict budgetary process did not seem to allow for any leeway at the time, attempts at dialogue were initiated, and the new general health manager seemed somewhat optimistic at the time that future decisions would acknowledge the health care point of view to a greater extent than had happened in the past. Further, the new general health manager seemed to have the trust of the city administration as well as an opportunity to build a bridge between clinical professionals and the city administration.

There is still some of that old hatred of the upper classes, so to speak. They (old management) were able to build a kind of idea among the clinical employees that the city administration is trying to thwart every effort and constrict all the resources to the bare minimum. Now we have this new (general health) manager, he's different. He seems to be open-minded, talks with us as well as the clinical professionals...I do think that we will get development efforts moving forward now. (Deputy chief mayor)

However, the deputy chief mayor and the general health manager interviewed for this study have since resigned. Only the latter position has been filled (by a temporary substitute) which suggests the difficult and contradictory conditions in the organization remain.

\title{
5. Discussion
}

The FHC was constructed as a network type of provider of health care services by the surrounding municipalities, but the power of decision was ultimately granted to the main city. One purpose of this arrangement was to seek financial savings. In order to realize these wellintended financial objectives, the city mayor focused on financial accountability and tried to push that accountability through the budgets and performance measurement into the health care organization with an authoritative approach. However, the FHC's budget was constantly exceeded and the role of the budget as a steering mechanism in the FHC seems weak in light of our empirical findings. At the organizational level, we found different blame game strategies as an outcome of conflicting accountabilities (see Hood, 2011). Clinical professionals defend themselves against accusations of overspending by employing various rhetorical strategies, combined with the non-delegation of budget accountability to the clinic 
level. Constant replacements in the position of the general health manager and the difficulties in recruiting doctors can be seen as a possible use of agency strategies in the organization. Understaffing in the health clinics has led to increases in treatment waiting lists and weakened the reputation of the FHC among clinical professionals and the citizens of the region. The problems in the FHC covered by the media have contributed to this bad reputation being circulated nationwide.

Messner (2009) warns about ethical conflicts on the individual level that result from increased emphasis on measurable aspects of accountability. In a similar way, Roberts (2009) sees the increased emphasis on transparency and the associated performance measures as problematic. These authors base their views on Butler (2005), who determines the responsibility of the individuals by way of the groups that they choose to associate themselves with. This individual responsibility may manifest through decisions, such as resignations or difficulties in fulfilling positions as evidenced in our case FHC. Possible causes for ethical contradictions on the individual level in the FHC include the mismatch between individual or professional views and the financial accountability driven by the city management. However, our findings indicate that clinical professionals are not passively submitting to this ethos but utilize different defensive tactics, characterized in this study as behavior similar to the blame game described by Hood $(2002,2011)$. The purpose of such blame game tactics is, in line with the clinical ethos, to preserve self-integrity and the necessary resources to provide good quality care for the patients. These actions demonstrating medical professionals' resistance can also be seen as a form of democratic accountability.

Bovens (1998) considers active resistance to management to be a wholly legitimate course of action in the face of serious conflict between organizational goals and public morale. Some examples in our case include demands by the health professionals for the city management's active responsibility, prioritizing quality patient care over financial considerations as well as the critical views expressed in the media. Previous accounting research has analyzed the democratic accountability and resistance by the service users to managerial forms of accountability (e.g., Cooper and Johnston, 2012; Smyth 2012). In the FHC, however, we found that clinical professionals utilized democratic accountability to actively resist financial accountability. This finding contributes to the different forms of expressing democratic accountability within a complex public-sector organization, and by providing an example of one leading profession acting on the basis of citizenship (cf. Bovens, 1998; Smyth, 2012).

Problems associated with democratic accountability in the organization appeared as political failures of the politicians to agree on issues, including the closing of small clinics. This is explained by the main city politicians' reluctance to make decisions that would reduce the service level provided to the local electorate. Moreover, in the FHC administration, the surrounding municipalities are limited to an advisory role through the health care division, while decisions concerning the FHC are made at the level of the basic welfare board, comprising members exclusively drawn from the main city's municipal council. Accounting could have an important intermediary role between network partners (Kurunmäki and Miller 
2011), but in our case, the surrounding municipalities felt that the reporting of financial information between municipalities was insufficient. Borowiak (2011) sees punishability as a central aspect of democratic accountability. However, the surrounding municipalities had only limited means to control the main city' decisions concerning the FHC. Owing to this inadequate democratic accountability design, the only option for the surrounding municipalities would be to disengage from the FHC organization. However, this would make it difficult for the smaller municipalities to provide the statutory level of services. Moreover, it would lead to difficult negotiations with the other municipalities on the terms of the dismantling of the organization.

Earlier studies have indicated that a move from hierarchical state entities to co-ordination of networks incorporates demands for increased dialogue to be expanded to citizen groups and other active stakeholders (Ahrens and Ferry, 2015; O'Dwyer and Unerman, 2007; Cordery et al., 2010). It is within the influence of the city mayor to choose to either exercise an authoritarian style of leadership or to engage the different stakeholders through dialogue. Within the democratic idea of providing services to the people sustainably, it might be in the long-term interests of different stakeholders to co-operate. Engaging different stakeholders through dialogue might make it possible to reconcile different views on accountability within an organization (Ahrens and Ferry, 2015; Goretzki and Messner, 2016). However, our findings confirm earlier results (Cordery et al., 2010; Lowe et al., 2012) that hierarchical practices and a focus on financial accountability are difficult to change into more interactive (or holistic) forms of accountability; particularly if the management has little will to engage in such practices. In our case, we observed only limited dialogue between the different stakeholder groups. Instead, we observed organizationally counter-productive behavior, characterized in this study as behavior characteristic of a blame game (Hood, 2002; 2011). It is noteworthy that what seems at the organizational level to be avoidance of responsibility or blame shifting, may be the rational and justified choices of individuals acting in a very complex situation. However, blame games are often detrimental to the organization in that they produce unproductive contradictions between different stakeholder groups.

Our empirical results indicate the need for dialogue between the parties to accountability relationships to tie the financial, health service, and political targets more closely together. This, as noted by Cordery et al. (2010), seems to demand strong leadership efforts supporting co-operation, both personally and among the professions to understand the views of the other parties affected. Our findings add to those of Cordery et al. (2010), who found that dialoguebased reconciliation between accountabilities is complicated by an unclear division of different accountabilities and the stability of old hierarchical practices. Our findings indicate that other obstacles to open dialogue are: a strong emphasis on financial accountability, a complex organizational structure, an unwillingness to provide relevant information, and a silo-style operating culture.

According to Roberts (2009), if there is no common vision and information is not exchanged between parties, the essential prerequisites for dialogue are missing. We elaborate on these characteristics by noting that although information might be exchanged, it can be flawed. 
Examples from our case include an unwillingness to provide financial information to other parties, errors in budgetary information, and deliberate reworking of financial reports for people's own purposes. Further, in a complex network organization, mutual dialogue allowing for a common vision can be difficult to instill even at the organization level. In a complex network context with a focus on financial pressures, the blame for any situation can be shifted between different bodies, and calculations can be deliberately made to seem more favorable to the interest group in question. In addition, the complexity of the democratic accountability concept offers opportunities to shift blame among stakeholders and organizational units. When accountabilities are lost among the complex organizational structures of a network, making informed decisions can become increasingly difficult.

In the FHC organization, the prominent accountabilities include financial accountability, professional accountability, and also democratic accountability. We see these different accountabilities as necessary parts of the organization, although in our case, the complexity of the organization coupled with accountabilities being weighted differently by different stakeholder groups has led to the problems in reconciling these multiple accountabilities. The interplay of these different accountability relations is complex, and results in a self-sustaining vicious circle of distrust, ethical issues, and a blame game that is hard to dismantle.

\section{Conclusions}

This study considered different instances of the blame game (Hood, 2002; 2011) in relation to financial, professional, and democratic accountabilities. We discussed the responsibility of individuals and the different reasons behind blame game type behavior. Further, we examined democratic accountability and citizenship in complex organizations under economic austerity. The study contributes to the literature by highlighting the multiple ways in which different forms of accountability, particularly democratic accountability, can manifest and be understood in a municipal organization with vertical and horizontal features.

This study set out to investigate the interplay of different accountabilities in a complex healthcare organization with the help of literature-based concepts of the blame game and dialogue. We identified failures in finding mutually acceptable solutions to organizational development needs (see, Cordery et al. 2010; O’Neill, 2002; Roberts, 2009), and instead found a situation characterized by separate and conflicting accountability views and the utilization of defensive tactics characterized in this study as blame game strategies. These problems were evident among the different organizational levels, units, and stakeholder groups involved in service provision (see, Hood, 2008, 2011).

The findings from this study make several contributions. First, we contribute to existing literature by empirically noting the different, conflicting accountabilities as a potential root of organizationally detrimental behavior (cf. Messner, 2009; Hood, 2008; 2011; Roberts, 2009) and illustrate the apparent rationality of Hood's (2011) different strategies in shifting blame in a networked public health care case organization. In our case, the conflict between 
professional and financial accountability seems to be key: the city management utilized policy-related strategies combined with agency strategies in directing blame toward individuals and the clinical professional group. In contrast, the clinical professionals seemed to utilize a presentational strategy to avoid blame. In addition, the inability of municipal politicians to agree on cost-saving measures initiated by the clinical management suggests a short-term view of democratic accountability and a reluctance to reduce the service level to the local electorate, and also indicate the utilization of policy and agency strategies.

Second, we amend the obstacles to consensus seeking dialogue discussed by Cordery et al. (2010) who found that dialogue-based reconciliation between accountabilities is complicated by an unclear division of different accountabilities and the stability of old hierarchical practices. Our findings indicate that other obstacles to open dialogue include a strong emphasis on financial accountability, a complex organizational structure, an unwillingness to provide relevant information, and a silo-style operating culture. One important professional group that is unwilling to engage in information exchange hampers the creation of dialogue and change in current practices. Further, we agree that if the drive for financial accountability is to be amended with a dialogical approach aiming to involve a larger group of stakeholders, an accountability system must be designed to support it (Brown, 2009; Ahrens and Ferry, 2015), citizens need to be empowered in decision making (Borowiak, 2011; Cooper and Johnston, 2012) and the senior management needs to have the will to engage in such dialogue (O'Dwyer and Unerman, 2007; Cordery et al., 2010; Lowe et al., 2012). This study also provides empirical evidence for the detrimental effects that the complex networked structure can have on democratic accountability.

Third, our results empirically contribute to the discussion on the blame game and the accountability-related rationales behind it. At an individual level, this study illustrates the blame game can be a rational reaction to situations characterized by moral contradictions due to an increasing emphasis on financial (and managerial) forms of accountability (Roberts, 2009; Messner, 2009). Further, a type of punishability (Borowiak, 2011) was evidenced in our case in clinical professionals resisting cost-saving demands based on financial accountability, thus providing an example of one leading profession acting on the basis of citizenship (Bovens, 2005; Cooper and Johnston, 2012; Smyth, 2012). Our study explains how individuals manage an uncertain situation involving contradictions between management's focus on financial savings, a professional ethos, and the wellbeing of citizens.

As this study is the first that we know of to empirically illustrate Hood's (2011) theory of the blame game in a case study, we would welcome further research on the subject. We would particularly welcome studies that uncover practices supporting co-operation and dialogue in network organizations. We also call for further research addressing the multifaceted nature of democratic accountability, particularly in network organizations, where democratic accountability can be seen in many different ways over time and is constantly redefined. 


\section{References}

Ahrens, T. (1997) Styles of accountability. Accounting. Organizations and Societv, Vol. 21 No 2/3 pp. 139-173.

Ahrens, T. and Chapman, C. (2002) The structuration of legitimate performance measures and management: day-to-day contests of accountability in a UK restaurant chain. Management Accounting Research, Vol. 13 No. 2 pp. 151-171.

Ahrens, T. and Ferry, L. (2015) Newcastle City Council and the grassroots: accountability and budgeting under austerity. Accounting. Auditing \& Accountability Journal, Vol. 28 No. 6, pp. 909-933.

Almquist, R., Grossi, G., van Helden, G. J. and Reichard, C. (2013) Public sector governance and accountability. Critical Perspectives on Accounting, Vol. 24 No. 7/8, pp. 479-487.

Alvesson, M. (2003) Beyond neopositivists, romantics and localists: a reflexive approach to interviews in organizational research. The Academv of Management Review, Vol. 28 No. 1, pp. 13-33.

Barberis, P. (1998) The New Public Management and a New Accountability. Public Administration, Vol. 76: 451-470.

Borowiak, C. T. (2011) Accountability \& Democracv - The Pitfalls and Promise of Popular Cotnrol. Oxford University Press. New York.

Bovens, M. (1998) The quest for responsibility - Accountability and citizenship in complex organisations. Cambridge University Press.

Bovens, M. (2005) Public accountability. In Ewan F., Lawrence Jr L., Pollitt, C. (eds.). The Oxford Handbook of Public Management. Oxford Handbooks.

Broadbent, J., Jacobs, K. and Laughlin, R. (2001) Organisational resistance strategies to unwanted accounting and finance changes: The case of general medical practice in the UK. Accounting. Auditing \& Accountabilitv Journal, Vol. 14 No. 5, p.565-586.

Brown, J. (2009) Democracy, sustainability and dialogic accounting technologies: Taking pluralism seriously. Critical Perspectives on Accounting, Vol. 20, pp. 313-342.

Butler, J. (2005) Giving an Account of Oneself. Fodham University Press. New York.

Chua, W. F. (1995) Experts, networks and inscriptions in the fabrication of accounting images: a story of the representation of three public hospitals. Accounting. Organizations and Societv, Vol. 20 No. 2-3, pp. 111-145.

Cochrane, A. (1993) From financial control to strategic management: the changing faces of accountability in British central government. Accounting. Auditing and Accountabilitv Journal, Vol. 6, No. 3, pp. 30-51.

Cooper, C. and Johnston, J. (2012) Vulgate accountability: instights from the field of football. Accounting Auditing \& Accountability Journal, Vol. 25, No. 4, pp. 602-634.

Cordery, C., Baskerville, R. and Porter, B. (2010) Control or collaboration? Contrasting accountability relationships in the primary health sector. Accounting. Auditing and Accountability Journal, Vol. 23, No. 6, pp. 793-813.

Day, P. and Klein, R. (1987) Accountabilities: Five public services. Tavistock, London.

Ezzamel, M. and Willmott, H. (1993) Corporate governance and financial accountability: recent reforms in the UK public sector. Accounting. Auditing and Accountability Journal, Vol. 6, No. 3, pp. 109-32.

Golden-Biddle, K. and Locke, K. (1993) Appealing work: an investigation of how ethnographic texts convince. Organization Science, Vol. 4, No. 4, pp. 595-616. 
Goddard, A. (2005) Accounting and NPM in UK local government - contributions towards governance and accountability. Financial Accountabilitv and Management, Vol. 21 No. 2, pp. 191-218.

Goretzki, L. and Messner, M. (2016) Coordination under uncertainty - A sensemaking perspective on cross-functional planning meetings. Oualitative Research in Accounting \& Management, Vol. 13 No. 1, pp. 92-126.

Gray, A. and Jenkins, B. (1993) Codes of accountability in the new public sector. Accounting. Auditing and Accountability Journal, Vol. 6, No. 3, pp. 75-99.

Gårseth-Nesbakk, L. and Kjærland, F. (2016) Precarious Investments and Blame Gaming Adverse Effects and the Inherent Danger of Simplification. Financial Accountability \& Management, Vol. 32 No. 3, pp. 281-308.

Hodges, R. (2012) Joined-up government and the challenge to accounting and accountability researchers. Einancial Accountabilitv and Management, Vol. 28 No. 1, pp. 26-51.

Hood, C. (2002) The risk game and the blame game. Government and Opposition, Vol. 37 No. 1, pp. $15-37$.

Hood, C. (2008) The risk game and the blame game. In Boin, A. (Ed.) Crisis Management, Volume III. London: Sage Publications, pp. 171-186.

Hood, C. (2011) The Blame Game. Spin, Bureaucracy, and Self-Preservation at Government. Princeton: Princeton University Press.

Humphrey, C., Miller, P. and Scapens, R. (1993) Accountability and accountable management in the UK public sector. Accounting. Auditing and Accountability Journal, Vol. 6, No. 3, pp. 7-29.

Hyvönen, T. and Järvinen, J. (2006) Contract-based budgeting in health care: a study of the institutional processes of accounting change. European Accounting Review, Vol. 15, No. 1, pp. 3-36.

Kurunmäki, L. (2004) A hybrid profession - the acquisition of management accounting expertise by medical professionals. Accounting Organizations and Society, Vol. 29 No., pp. 327-47.

Kurunmäki, L. and Miller, P. (2011) Regulatory hybrids: partnerships, budgeting and modernizing government. Management Accounting Research, Vol. 22, No. 4, pp. 220-41.

Lapsley, I., Kurunmäki, L. and Melia, K. (2003) Accountingization v. legitimation: a comparative study of the use of accounting information in intensive care. Management Accounting Research, Vol. 14, No. 2, pp. 112-39.

Lapsley, I. (2008) The NPM agenda: back to the future. Financial Accountabilitv \& Management, Vol. 24, No. 1, pp. 77-96.

Llewellyn, S. (1998) Pushing budgets down the line: ascribing financial responsibility in the UK social services. Accounting. Auditing \& Accountability Journal. Volume 11, No. 3, pp. 292308.

Lowe, A., Locke, J. and Lymer, A. (2012) The SEC's retail investor 2.0: Interactive data and the rise of calculative accountability. Critical Perspectives on Accounting, Vol. 23, No. pp. 183-200.

McKinnon, J. (1988) Reliability and validity in field research: some strategies and tactics. Accounting. Auditing \& Accountabilitv Journal, Volume 1, No. 1, pp. 34-54.

Messner, M. (2009) The limits of accountability. Accounting Organizations and Societv, Vol. 34, No. 8, pp. 918-938.

Mulgan, R. (2000) 'Accountability': An ever-expanding concept? Public Administration, Vol. 78 No. 3, pp. 555-573.

Mutiganda, J. C. (2013) Budgetary governance and accountability in public sector organisations: An institutional and critical realism approach. Critical Perspectives on Accounting, Vol. 24, No. 7/8, pp. 518-31. 
O'Dwyer, B. and Unerman, J. (2007) From functional to social accountability: Transforming the accountability relationship between funders and non-governmental development organisations. Accounting. Auditing \& Accountabilitv Journal. Vol. 20, Iss: 3, pp.446 - 471.

O’Neill, O. (2002) A Question of Trust. Cambridge University Press.

Papadopoulos, Y. (2003) Cooperative forms of governance: Problems of democratic accountability in complex environments. European Journal of Political Research, Vol. 42, pp. 473-501.

Pierre, J. (2000) Introduction: Understanding governance. In J. Pierre (ed.) Debating Governance. Oxford University Press, pp. 1-10.

Rhodes, R. A. W. (1997) Understanding Governance. Public networks, governance, reflexivity and accountability. Open University Press.

Rhodes, R. A. W. (2007) Understanding Governance: Ten Years On. Organization Studies, Vol. 28 No. 8, pp. 1243-1264.

Roberts, J. (2003) The manufacture of corporate social responsibility; constructing corporate sensibility. Organization, Vol. 10 No. 2, pp. 249-265

Roberts, J. (2009) No one is perfect: the limits of transparency and an ethic for intelligent accountability. Accounting Organizations and Societv, Vol. 34, No. 8, pp. 957-70.

Roberts, J. and Scapens, R. (1985) Accounting Systems and Systems of Accountability Understanding Accounting Practices in their Organizational Context. Accounting Organizations and Societv, Vol. 19, No. 2, pp. 443-56.

Romzek, B. S. and Dubnick, M. J. (1987) Accountability in the public sector: Lessons from the Challenger tragedy. Public Administration Review, Vol. 47, pp. 227-38.

Silverman, D. (2001) Interpreting Qualitative Data. Methods for Analysing Talk, Text and Interaction. $2^{\text {nd }}$ Ed. (first published 1993). London: Sage Publications.

Sinclair, A. (1995) The chameleon of accountability: forms and discourses. Accounting. Organizations and Societv, Vol. 20, Nos. 2/3, pp. 219-237.

Smyth, S. (2012) Contesting public accountability: A dialogic exploration of accountability and social housing. Critical Perspectives on Accounting, Vol. 23, No. 3, pp. 230-43.

Yin, R. K. (1984). Case study research: Design and methods. Newbury Park, CA: Sage. 


\section{Appendix 1}

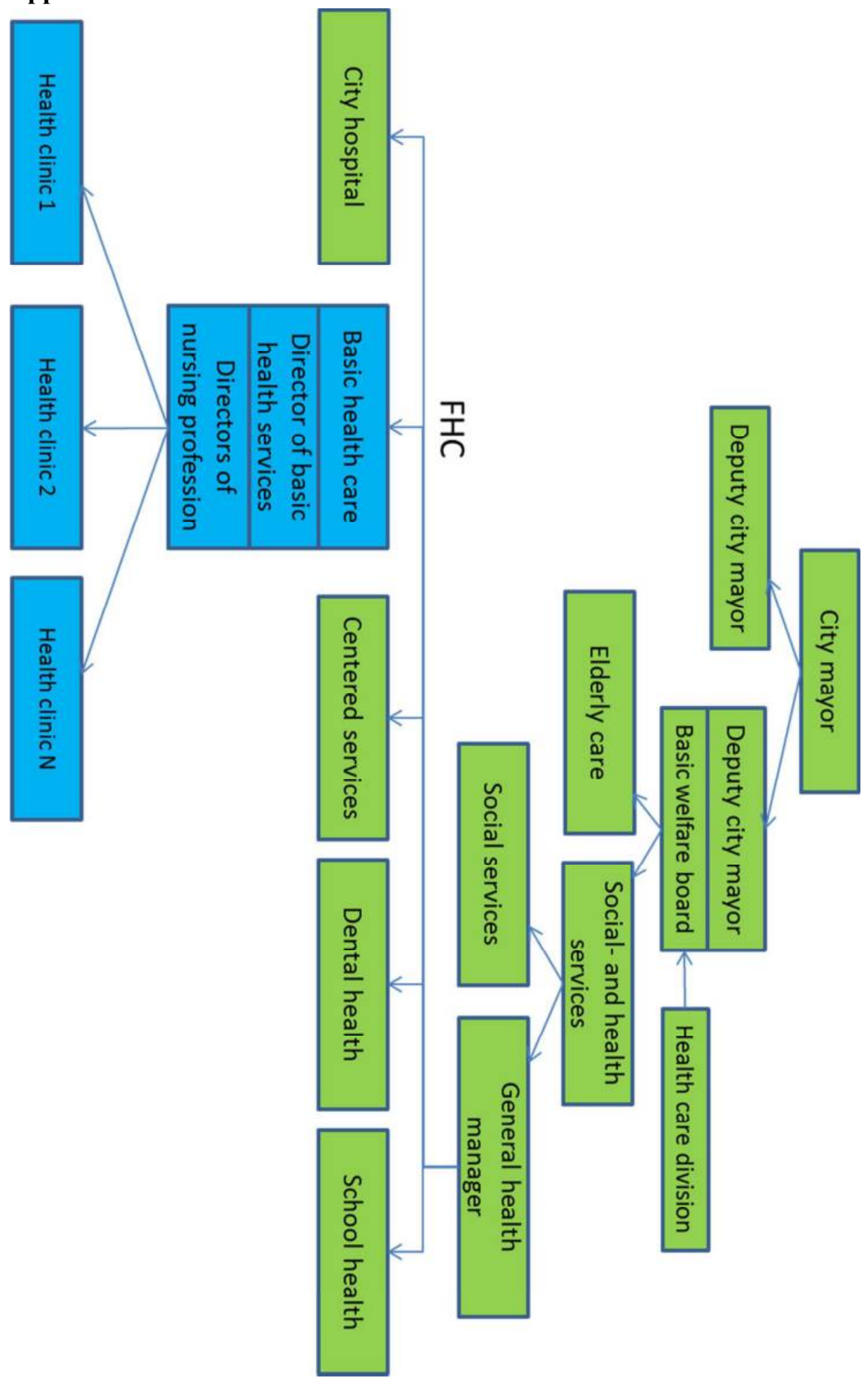

Figure 1 - Main city structure and the FHC

\section{(c) Emerald Publishing Limited}

This is a pre-print of a paper and is subject to change before publication. This pre-print is made available with the understanding that it will not be reproduced or stored in a retrieval system without the permission of Emerald Publishing Limited. 
(C) Emerald Publishing Limited

This is a pre-print of a paper and is subject to change before publication. This pre-print is made available with the understanding that it will not be reproduced or stored in a retrieval system without the permission of Emerald Publishing Limited. 


\title{
Appendix 2 - List of interviews
}

\section{First round of interviews}

Internal auditing chief and external auditor 6.2.2013

Accounting chief 11.2.2013

Financial manager of the social and health services 11.2.2013

Director of nursing profession 19.2.2013

Director of basic health care 19.2.2013

Accounting service chief and accounting secretary 17.4.2013

Financial manager of the social and health services 24.4.2013

\author{
Second round of interviews \\ Health clinic 1 \\ Nurse 1, 11.10.2013 \\ Nurse2, 11.10.2013 \\ Doctor1, 11.10.2013 \\ Doctor2, 11.10.2013 \\ Deputy chief physician, 11.10.2013 \\ Head nurse, 22.10.2013
}

Health clinic 2

Nurse1, 21.10.2013

Nurse2, 21.10.2013

Doctor1, 31.10.2013

Doctor2, 31.10.2013

Deputy chief physician, 22.10.2013

Head nurse, 22.10.2013

Health clinic 3

Nurse1, 9.10.2013

Nurse2, 15.10.2013

Doctor1, 18.10.2013

Doctor2, 18.10.2013

Deputy chief physician, 18.10 .2013

Head nurse, 18.10.2013

\section{Third round of interviews}

Internal auditing chief and city financial chief 7.2.2014

Deputy city mayor 18.2.2014

General health manager 18.2.2014

Development officer 4.3.2014

Director of nursing services 7.3.2014

Relocated general health manager 7.3.2014 